\title{
Evaluatie Nieuw Mosselpercelen \\ Technische rapportage TO bemonstering vispopulaties 2020
}

Auteur(s): Ingeborg Mulder ${ }^{1}$, Ingrid Tulp ${ }^{1}$, Jetze van Zwol ${ }^{1}$, Bram Couperus ${ }^{1}$, Marnix van Stralen ${ }^{2}$, Henrice Jansen ${ }^{1}$

${ }^{1}$ Wageningen Marine Research ${ }^{2}$ Bureau Marinx
Wageningen University \&

Research rapport $\mathrm{C} 117 / 20$ 


\section{Evaluatie Nieuwe Mosselpercelen}

Technische rapportage T0 bemonstering vispopulaties 2020

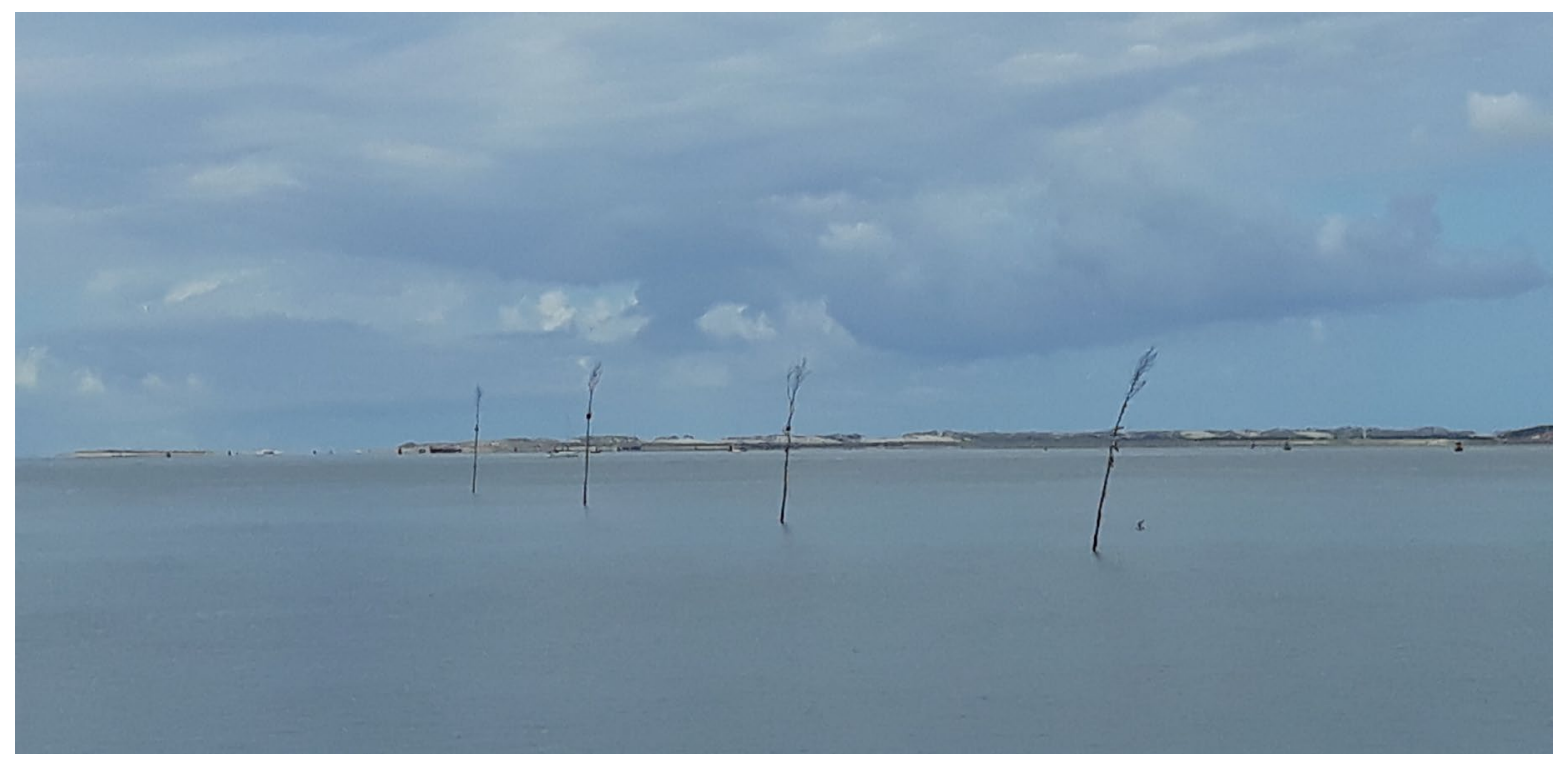

Auteur(s): $\quad$ Ingeborg Mulder ${ }^{1}$, Ingrid Tulp ${ }^{1}$, Jetze van $\mathrm{Zwol}^{1}$, Bram Couperus ${ }^{1}$, Marnix van Stralen ${ }^{2}$, Henrice Jansen ${ }^{1}$

${ }^{1}$ Wageningen Marine Research ${ }^{2}$ Bureau Marinx

Dit onderzoek is uitgevoerd door Wageningen Marine Research en gesubsidieerd door het Ministerie van Landbouw, Natuur en Voedselkwaliteit, in het kader van het Beleidsondersteunend onderzoekthema 'Duurzame voedselvoorziening \& -productieketens \& Natuur' (projectnummer BO-43-023.02-062)

Wageningen Marine Research

Yerseke, December 2020

VERTROUWELIJK Nee

Wageningen Marine Research rapport C117/20 


\section{(c) Wageningen Marine Research}

Wageningen Marine Research, instituut binnen de rechtspersoon Stichting

Wageningen Research, hierbij

vertegenwoordigd door

Dr.ir. J.T. Dijkman, Managing director

KvK nr. 09098104,

WMR BTW nr. NL 8113.83.696.B16.

Code BIC/SWIFT address: RABONL2U

IBAN code: NL 73 RABO 0373599285
Wageningen Marine Research aanvaardt geen aansprakelijkheid voor gevolgschade, noch voor schade welke voortvloeit uit toepassingen van de resultaten van werkzaamheden of andere gegevens verkregen van Wageningen Marine Research. Opdrachtgever vrijwaart Wageningen Marine Research van aanspraken van derden in verband met deze toepassing.

Alle rechten voorbehouden. Niets uit deze uitgave mag weergegeven en/of gepubliceerd worden, gefotokopieerd of op enige andere manier gebruikt worden zonder schriftelijke toestemming van de uitgever of auteur. 
Keywords: T0 bemonstering, vissen, optimalisatie mosselpercelen

Opdrachtgever: Ministerie van Landbouw, Natuur en Voedselkwaliteit T.a.v.: Dhr. J.J.M. Kouwenhoven

Bezuidenhoutseweg 73

2594 AC Den Haag

BO-43-023.02-062

Dit rapport is gratis te downloaden van https://doi.org/10.18174/537190

Wageningen Marine Research verstrekt geen gedrukte exemplaren van rapporten.

Wageningen Marine Research is ISO 9001:2015 gecertificeerd.

Foto omslag: Ingeborg Mulder 



\section{Inhoud}

$\begin{array}{lr}\text { Samenvatting } & 6\end{array}$

$\begin{array}{llr}1 & \text { Inleiding } & 7\end{array}$

$\begin{array}{lll}1.1 & \text { Achtergrond } & 7\end{array}$

$\begin{array}{lll}1.2 & \text { Doelstelling } & 7\end{array}$

2 Methode $\quad 8$

2.1 Bemonsterde locaties $\quad 8$

$\begin{array}{lll}2.1 .1 & \text { Keuze van locaties } & 8\end{array}$

2.1.2 Overzicht van uitgevoerde mosselkor trekken en geplaatste kubben $\quad 8$

2.2 Vistuigen 10

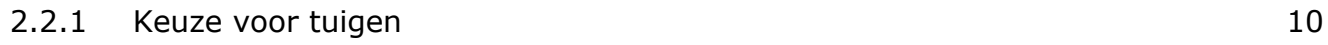

$\begin{array}{ll}2.2 .2 \text { Beschrijving tuigen } & 10\end{array}$

$\begin{array}{lll}2.3 & \text { Bemonstering } & 11\end{array}$

2.3.1 Mosselkor met omhullingkuil $\quad 11$

$\begin{array}{ll}2.3 .2 \text { Kubben } & 12\end{array}$

$\begin{array}{llr}3 & \text { Resultaten } & 13\end{array}$

$\begin{array}{lll}3.1 & \text { Vangsten met mosselkor } & 13\end{array}$

3.2 Vangsten met kubben $\quad 16$

4 Dankwoord $r$

$\begin{array}{lr}\text { Literatuur } & 20\end{array}$

$\begin{array}{lr}\text { Verantwoording } & 21\end{array}$ 


\section{Samenvatting}

In het kader van het Mosselconvenant zijn afspraken gemaakt over de optimalisatie van de kweekpercelen in de westelijke Waddenzee. Dit houdt in dat er nieuwe kweekpercelen voor mosselen uitgegeven worden op locaties waarvan men verwacht dat goede rendementen gerealiseerd kunnen worden en er op andere locaties percelen worden opgegeven. Dit resulteert in de aanleg van 850 ha nieuw kweekareaal. De schaalgrootte van deze maatregel is van dien aard, dat te verwachten valt dat deze maatregel effect kan hebben op populatieniveau van soorten die aangetrokken worden door de kweekmosselen als habitat in de vorm van hard substraat. De aan mosselen geassocieerde soorten betreffen bodemdieren, maar mogelijk ook vissoorten.

In 2018 en 2019 zijn reeds T0 bemonsteringen (beoordeling voor aanleg) voor macrobenthos uitgevoerd en daarmee zijn de bodemdiergemeenschappen voor aanleg van nieuwe percelen in kaart gebracht. De huidige studie is erop gericht in kaart te brengen welke vissoorten in welke dichtheden aanwezig zijn in de gebieden waar nieuwe percelen voorzien zijn, om zo in de toekomst vast te kunnen stellen wat het effect van aanleg geweest is op deze soorten. De voorliggende technische rapportage beschrijft de methode en de voorlopige resultaten van de T0 bemonstering. Nadere analyse en discussie zal plaatsvinden wanneer de bemonsteringen uitgevoerd zijn nadat percelen in gebruik genomen zijn. Naast de aangetroffen vissoorten in de vangsten zijn ook de garnalen, krabben, kreeften, stekelhuidigen (zeesterren) en inktvissen geregistreerd en gerapporteerd.

Er zijn vijf perceellocaties bemonsterd: Oosterom, Meep, Inschot in de Vliestroom komberging en Scheurrak en Scheer in de Marsdiep komberging. De bemonstering is uitgevoerd in september 2020 met een combinatie van actieve en passieve vistuigen, omdat elk tuig een bepaalde efficiëntie en selectiviteit heeft. Bovendien verschilt de ondergrond in de T0 en T1, waardoor we nu al rekening moesten houden met de mogelijkheden voor bemonstering in de T1. Als actief tuig is gebruik gemaakt van een mosselkor met omhullingskuil en als passief tuig is gebruik gemaakt van kubben. Beide tuigen zijn geschikt voor het bemonsteren van bodemvissen.

Totaal zijn er 77 trekken uitgevoerd met de mosselkor. Het aantal trekken varieerde daarbij tussen de 10 en 21 per gebied en de treklengte was $\pm 50 \mathrm{~m}$. Het aantal gevangen vissoorten per gebied varieerde tussen de drie en acht en het totaal aantal soorten tussen de 10 en 19. Grondels waren in de grootste aantallen aanwezig (78-1658 per ha). Daarnaast zijn botervis, zeedonderpad, kleine zeenaald, schar, schol, sprot, tong en vijfdradige meun aangetroffen. Het zijn vooral kleinere soorten of juvenielen van grotere soorten die zijn gevangen tijdens deze bemonstering.

Er zijn in totaal 152 kubben uitgezet en iedere kub heeft 24 uur in het water gestaan. Per gebied waren er vier tot 12 bemonsteringslocaties, met vier kubben per locatie. In 68 van de 152 kubben zijn vissen aangetroffen. Het aantal gevangen vissoorten per gebied varieerde tussen de één en drie en het totaal aantal soorten tussen de vier en negen. Er zijn vijf verschillende vissoorten gevangen waarvan de vijfdradige meun de meest aangetroffen soort is, gevolgd door steenbolk. Van de overige drie soorten - aal, puitaal en zeedonderpad - werd slechts één exemplaar aangetroffen. 


\section{$1 \quad$ Inleiding}

\section{$1.1 \quad$ Achtergrond}

In 2008 is het Convenant transitie Mosselsector en Natuurherstel Waddenzee (kortweg Mosselconvenant) gesloten tussen het ministerie van LNV, de mosselsector en natuurorganisaties. Het Mosselconvenant heeft als ambitie de mosselzaadvisserij af te bouwen, het verlies aan vangstmogelijkheden voor mosselzaad te compenseren met de aanleg van MZI's (mosselzaad invanginstallaties) en dat in een zodanig tempo dat er perspectief blijft voor een economisch rendabele sector (Ministerie van Landbouw Natuur en Voedselkwaliteit et al., 2008). In het kader hiervan zijn afspraken gemaakt over de optimalisatie van de kweekpercelen. Praktisch houdt dit in dat bestaande percelen met een laag rendement worden verplaatst naar locaties met betere condities waar nu geen kweek plaatsvindt. De schaalgrootte van deze beheersmaatregel is van dien aard dat het mogelijk is dat deze effect kan hebben op populatieniveau van soorten die aangetrokken worden door het hard substraat dat de mosselpopulaties bieden. Deze geassocieerde soorten betreffen bodemdieren, maar mogelijk ook bepaalde vissoorten.

De optimalisatie is een unieke situatie (de laatste optimalisatie dateert van 1995) en biedt de mogelijkheid om het effect van mosselpercelen op vispopulaties en bodemdiergemeenschappen gericht te onderzoeken. De rol van mosselbedden voor vispopulaties is in onderzoek tot op heden onderbelicht gebleven.

De aanleg van nieuwe mosselpercelen biedt de kans om effecten van de aanleg van grote oppervlaktes aan hard substraat op natuurwaarden te onderzoeken (totaal 850 ha. aan nieuwe percelen). Het streven is dat de percelen in 2021 in gebruik genomen worden. In 2018 en 2019 zijn reeds T0 bemonsteringen voor benthos uitgevoerd, waarmee de bodemdiergemeenschappen vóór aanleg van nieuwe percelen reeds in kaart gebracht. Dit onderzoek is uitgevoerd binnen het KOMPRO programma, gefinancierd door de PO Mosselcultuur. De T0 voor vis is uitgevoerd in 2020 (dit rapport), gefinancierd door het ministerie van LNV.

\subsection{Doelstelling}

De kennisvraag is welk effect de aanleg en het gebruik van mosselpercelen heeft op vispopulaties in de Westelijke Waddenzee. Meer concreet is de kennisvraag in dit rapport welke vissoorten momenteel aanwezig zijn op de voor nieuwe percelen beoogde locaties.

Dit rapport beschrijft de uitvoering van de daartoe uitgevoerde T0 bemonstering. De resultaten worden kort gerapporteerd. Een meer uitvoerige data analyse zal worden uitgevoerd na de T1 (nadat de percelen in gebruik zijn genomen). De uitkomsten van het onderzoek zijn van belang om het samenstel van afspraken en maatregelen, zoals vastgelegd in het Mosselconvenant, te kunnen beoordelen op hun betekenis voor de natuurwaarden van de Waddenzee. 


\section{$2 \quad$ Methode}

\section{$2.1 \quad$ Bemonsterde locaties}

\subsubsection{Keuze van locaties}

Het voorgenomen areaal nieuwe percelen bestaat uit (i) kleine stroken die vastgelegd worden aan bestaande percelen, (ii) een nieuw gebied waar momenteel geen kweek plaatsvindt en (iii) grotere perceel blokken die naast of in de buurt van bestaande percelen geplaatst worden. Voor de benthos T0 bemonstering zijn negen locaties geselecteerd waar een relatief groot areaal nieuwe percelen voorzien is en waar dus voldoende locaties bemonsterd kunnen worden voor een representatieve ecologische evaluatie. Om capaciteitsredenen (tijd, beschikbaar aantal kubben) zijn van deze gebieden vijf gebieden geselecteerd waar de visbemonstering uitgevoerd is. Deze gebieden zijn zo gekozen dat er een goede ruimtelijke spreiding is. Om capaciteitsredenen zijn er ook geen referentiegebieden bemonsterd. Voorkomen en trends in vispopulaties worden jaarlijks bepaald tijdens de DFS survey (Bolle et al. 2019). Deze kunnen gelden als een baseline voor ontwikkeling van het visbestand in de Waddenzee.

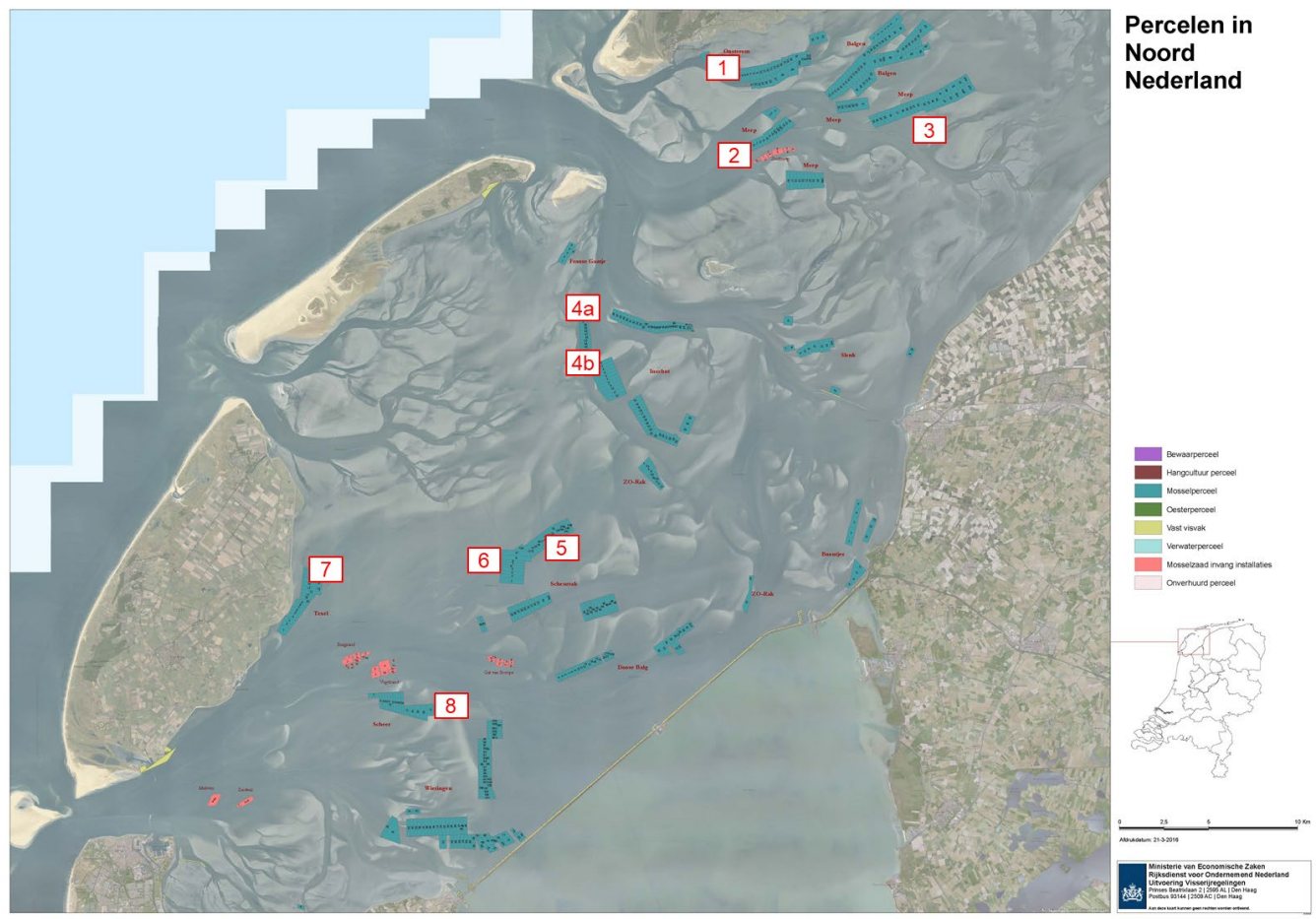

Figuur 1. Bemonsteringsgebieden voor de TO bemonsteringen op de locaties waar nieuwe percelen voorzien zijn in de Waddenzee:

(1) Oosterom (benthos 2018/2019 + vis 2020),

(2) Meep (benthos 2018/2019+ vis 2020),

(3) Gat van Pietje (benthos 2018)

(4a) Inschot (benthos 2018/2019 + vis 2020)

(4b) Inschot (benthos 2018/2019)

(5) Scheurrak (benthos 2018/2019+vis)

(6) Scheurrak-oost (benthos 2018)

(7) Texel (benthos 2018)

(8) Scheer (benthos 2018/2019 + vis 2020).

\subsubsection{Overzicht van uitgevoerde mosselkor trekken en geplaatste kubben}

Per individueel perceel zijn minimaal twee transecten bevist met de mosselkor. Per gebied zijn minimaal 10 trekken uitgevoerd (Figuur 2). 


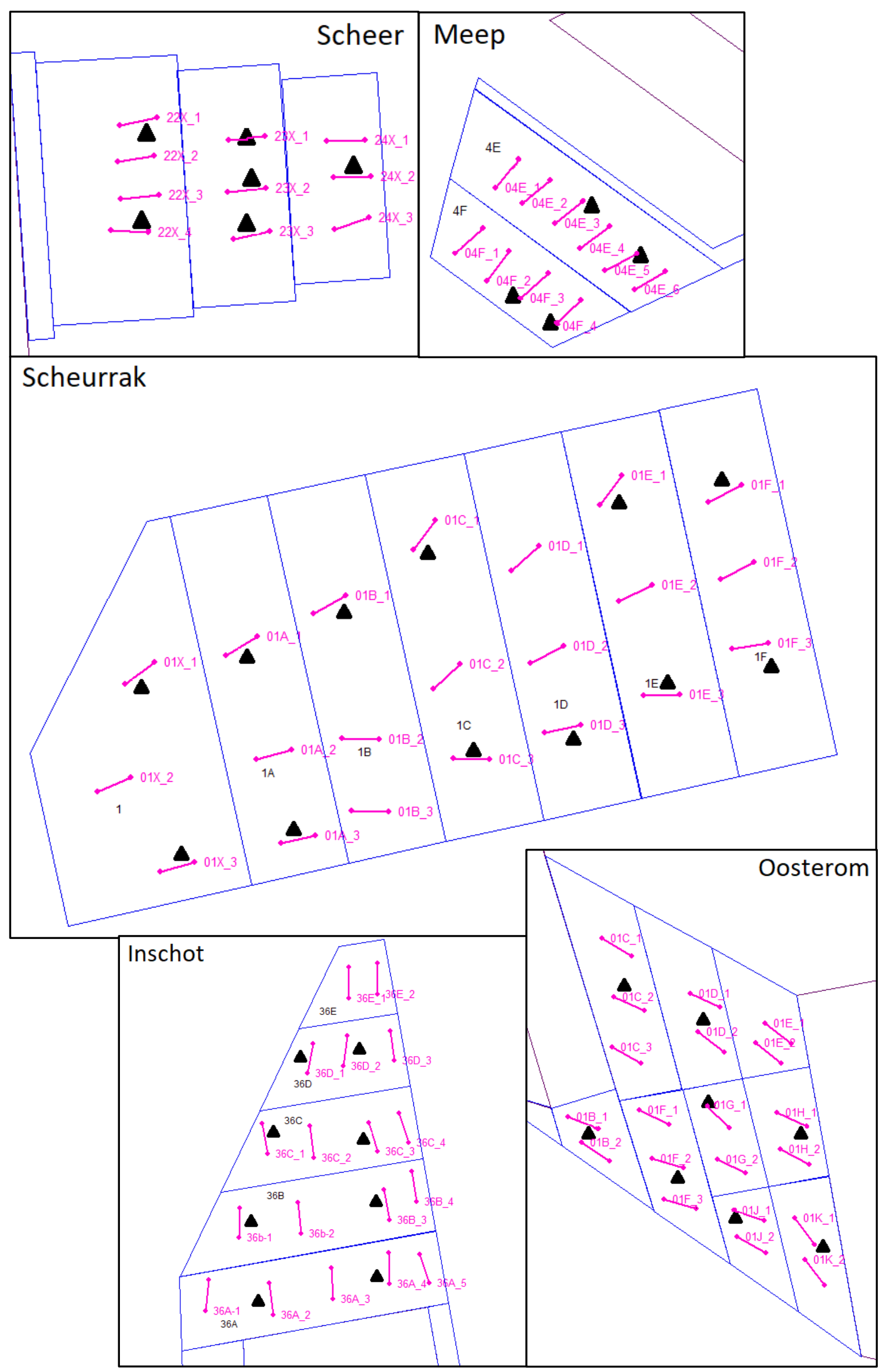

Figuur 2. Locaties van trekken met mosselkor (roze lijn) en van geplaatste kubben (zwarte driehoek) in de vijf gebieden: Scheer, Meep, Scheurrak, Inschot en Oosterom. Elke zwarte driehoek vertegenwoordigd vier geplaatste kubben. 
Tabel 1. Aantal trekken met mosselkor en kubben locaties per onderzoeksgebied.

\begin{tabular}{|l|c|c|}
\hline Gebied & $\begin{array}{l}\text { Aantal trekken per gebied met } \\
\text { mosselkor }\end{array}$ & $\begin{array}{l}\text { Aantal kubben-locaties per } \\
\text { gebied (4 kubben/locatie) }\end{array}$ \\
\hline Scheer (SR) & 10 & 6 \\
\hline Meep (MP) & 10 & 4 \\
\hline Scheurrak (SK) & 21 & 12 \\
\hline Inschot (IN) & 18 & 8 \\
\hline Oosterom (OM) & 20 & 8 \\
\hline
\end{tabular}

\subsection{Vistuigen}

\subsubsection{Keuze voor tuigen}

Er is gekozen om te bemonsteren met een combinatie van actieve (voortgesleept) en passieve vistuigen. De voor dit onderzoek ingezette tuigen zijn geschikt voor het bemonsteren van bodemvissen zowel op zandige bodem als een met mosselen bedekte bodem. Als gesleept vistuig is gebruik gemaakt van een mosselkor met omhullingskuil. De mosselkor wordt ook gebruikt in de mosselzaadvisserij om op mosselzaad te vissen of mosselen te oogsten op percelen. Kleinere vissoorten kunnen ontsnappen uit de kor vanwege de grote maaswijdte. Daarom is om de kor een fijnmazig net aangebracht om zo ook kleinere vissoorten te vangen. De kor vangt ook de soorten die tussen de mosselen zitten, omdat de mosselen mee op worden gevist. De mosselkor met omhullingskuil is eerder gebruikt binnen het PRODUS project (Glorius et al. 2012).

Als passief tuig is gebruik gemaakt van kubben, die ook ingezet worden in onder meer de aalvisserij. Meerdere kubben kunnen met behulp van een zijlijn aan een hoofdlijn worden bevestigd, met de achterkant van de kub naar de hoofdlijn gericht, die op de zeebodem wordt verankerd. Vissen moeten actief de kubben inzwemmen. Omdat de lijn op de stroom wordt gezet ontstaat er een luwte nabij de ingang van de kub, waardoor soorten sneller de kub zullen inzwemmen en deze mogelijk gebruiken als schuilplaats. Er is geen aas aangebracht in de kubben.

\subsubsection{Beschrijving tuigen}

\section{Mosselkor}

De kor bestaat uit een metalen raamwerk ( 1.80 breed $\times 0.7 \mathrm{~m}$ hoog) met daarin een net. De onderzijde van het net bestaat uit metalen ring (maliënkolder) in verband met de het slepen over de bodem. De maaswijdte van het net is 6 tot $8 \mathrm{~cm}$ volle maas. Aan de onderkant van het frame zit een stalen pijp (zogenaamde slikknuppel) van ongeveer $4 \mathrm{~cm}$ die over de bodem wordt gesleept en ervoor zorgt dat de kor niet te diep wegzakt in een zachte bodem. Om de mosselkor is een omhullingskuil (20 $\mathrm{mm}$ volle maas) aangebracht van ca. $3.20 \mathrm{~m}$ lang (Figuur 3). De staart van de omhullingskuil wordt dichtgebonden tijdens de trek. Via de staart kan de omhullingskuil ook geleegd worden. Nadat de omhullingskuil geleegd is, wordt de kor geleegd door deze ondersteboven te hangen. Zie verder ook Glorius et al. (2012).

\section{Kubben}

In het onderzoek is een combinatie van twee type kubben gebruikt, relatief 'platte' (Figuur 4, links) en 'ronde' (Figuur 4, rechts) exemplaren. De specificaties van de platte kubben zijn $100 \mathrm{~cm}$ lang, $45 \mathrm{~cm}$ breed en $25 \mathrm{~cm}$ hoog en van de ronde kubben $100 \mathrm{~cm}$ lang, $30 \mathrm{~cm}$ breed en $30 \mathrm{~cm}$ hoog. Alle kubben hebben een maaswijdte van $22 \mathrm{~mm}$ volle maas. 


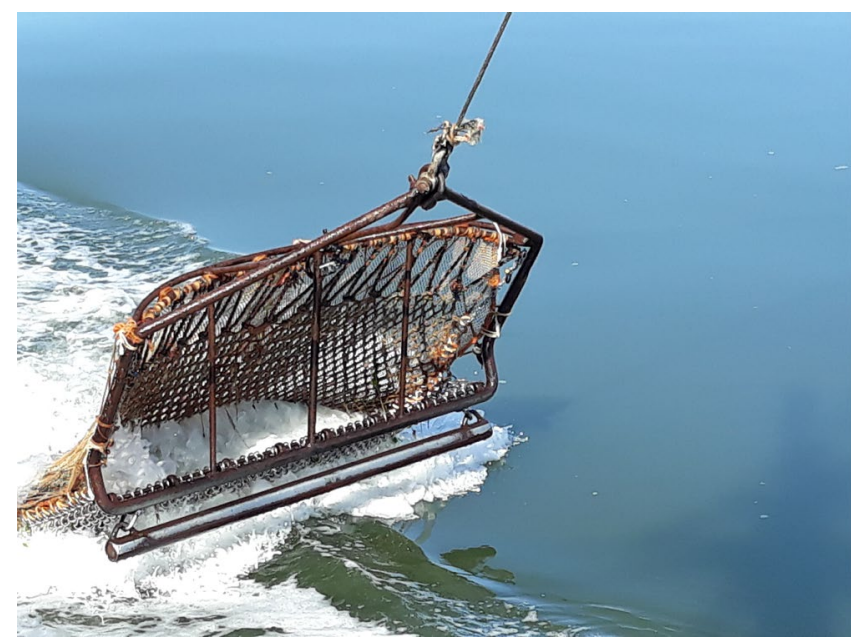

Figuur 3. Mosselkor met omhullingskuil.
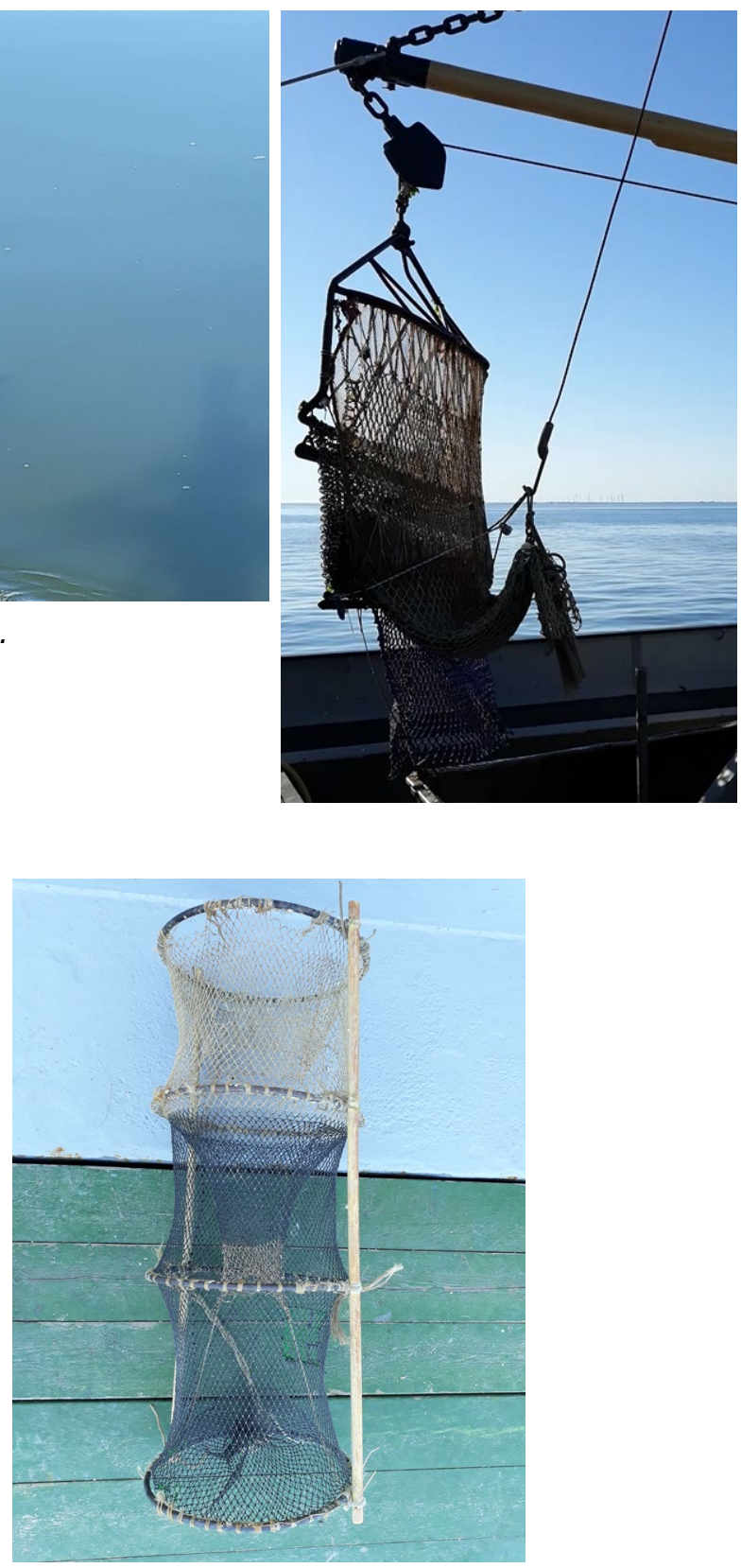

Figuur 4. Twee typen kubben die zijn gebruikt: kubben met relatief 'platte' (links) en 'ronde' (rechts) hoepels.

\subsection{Bemonstering}

De visbemonsteringen zijn uitgevoerd in september 2020. Deze periode sluit aan bij andere visbemonsteringen zoals de Demersal Fish Survey (DFS) en omdat de periode waarin de meeste soorten en de hoogste dichtheden vis in de Waddenzee aanwezig zijn.

\subsubsection{Mosselkor met omhullingkuil}

De lengte van de trek werd afgestemd op het slepen van een mosselkor op een mosselperceel met volwassen mosselen en zodanig lang dat de kor niet vol was bij het halen. Dat laatste is nodig omdat bij een volle kor een onbekend deel van de potentiele vangst in het beviste traject wordt gemist en daarmee de vangstefficiëntie veranderd. De vissnelheid was circa 2.5 mijl. De geviste afstand werd bijgehouden met GPS.

De werkelijk geviste trekafstand werd bepaald door de volgende posities te loggen: 

a. Moment van vieren van de mosselkor
b. Moment van vastzetten vislier, vanaf dan werd er gesleept
c. Moment van halen van de mosselkor
d. Moment dat de mosselkor boven water kwam

Daarna zijn de volgende afstanden berekend:

- $\quad$ Vieren = afstand die het schip heeft afgelegd tijdens het vieren van de mosselkor (b-a)

- $\quad$ Vast = afgelegde afstand van de kor over de bodem (c-b)

- $\quad$ Halen $=$ afstand die het schip heeft afgelegd tijdens het halen van de mosselkor ( $d-c)$

Trekafstand $=(0.25 *($ afstand vieren + halen $))+$ afstand vast

Bij elke trek is tegen de stroom in gevist en is getracht om de diepte gelijk te houden gedurende de gehele trek. Diepte en andere omgevingsfactoren zijn per trek genoteerd maar worden op een later moment geanalyseerd. Daarnaast ligt elke trek minimaal $20 \mathrm{~m}$ van de perceelgrens af, omdat daar mogelijk minder mosselen gezaaid zijn en om effecten van omliggende gebieden te minimaliseren.

Bij het binnenhalen van de mosselkor is eerst de vangst van de omhullingskuil in een aparte bak gestort, daarna is de kor leeggestort in een grotere bak. Voor het monster uit de kor is het volume van de mosselen geschat in liters. Van beide vangsten zijn foto's gemaakt en werden de monsters op dezelfde manier uitgezocht. Alle vissoorten werden tot de $\mathrm{cm}$ naar beneden afgerond gemeten. Bij grote vangsten is na het uitzoeken van de vis zo nodig een deelmonster genomen om er zeker van te zijn dat tussen de mosselen geen kleine vis is achtergebleven. Ook is een deelmonster genomen bij hoge dichtheden, met daarbij als uitgangspunt dat van de betreffende soort minimaal 50 exemplaren - voor zover in de vangst aanwezig - konden worden doorgemeten. Benthossoorten zijn geregistreerd in aantallen. Daarbij werden onderscheiden: zeesterren, brokkelsterren, krabben op soort (klein $(<2$ $\mathrm{cm}$ )/groot), heremietkreeften en garnalen. Daarnaast zijn ook inktvissen genoteerd. Kwallen, wieren en hydroïdpoliepen zijn niet meegenomen in de tellingen.

\subsubsection{Kubben}

Per locatie zijn meerdere lijnen van 200 m uitgezet, verankerd op de bodem. Eén kant van de lijn lag op het ene perceel en het uiteinde van de andere kant lag op het volgende perceel (Figuur 5). Eén lijn beviste dus twee percelen. Aan elk uiteinde werden vier kubben vastgemaakt met 7-10 m ruimte tussen elke kub. De buitenste drie kubben waren 'platte' kubben en de vierde binnenste kub was een 'ronde' kub (Figuur 5). In de kubben is geen aas gebruikt omdat dit te veel krabben zou aantrekken. Zoals eerder aangegeven zijn de kubben op de stroom geplaatst, waardoor er een luwte ontstond bij de opening van de kub, waar vis gebruik van kon maken en zo wellicht eerder de kub binnenzwom. De uiteinden van een kubbenlijn werden gekenmerkt door een rode vlag en een boei (Figuur 5). Alle kubben zijn uitgezet voor een periode van 24 uur en zijn daarna weer opgehaald. De vangst werd per kub geregistreerd en op dezelfde manier verwerkt als de vangst van de mosselkor. Aangezien de vangst per kub gering was, hoefden geen deelmonsters genomen te worden.

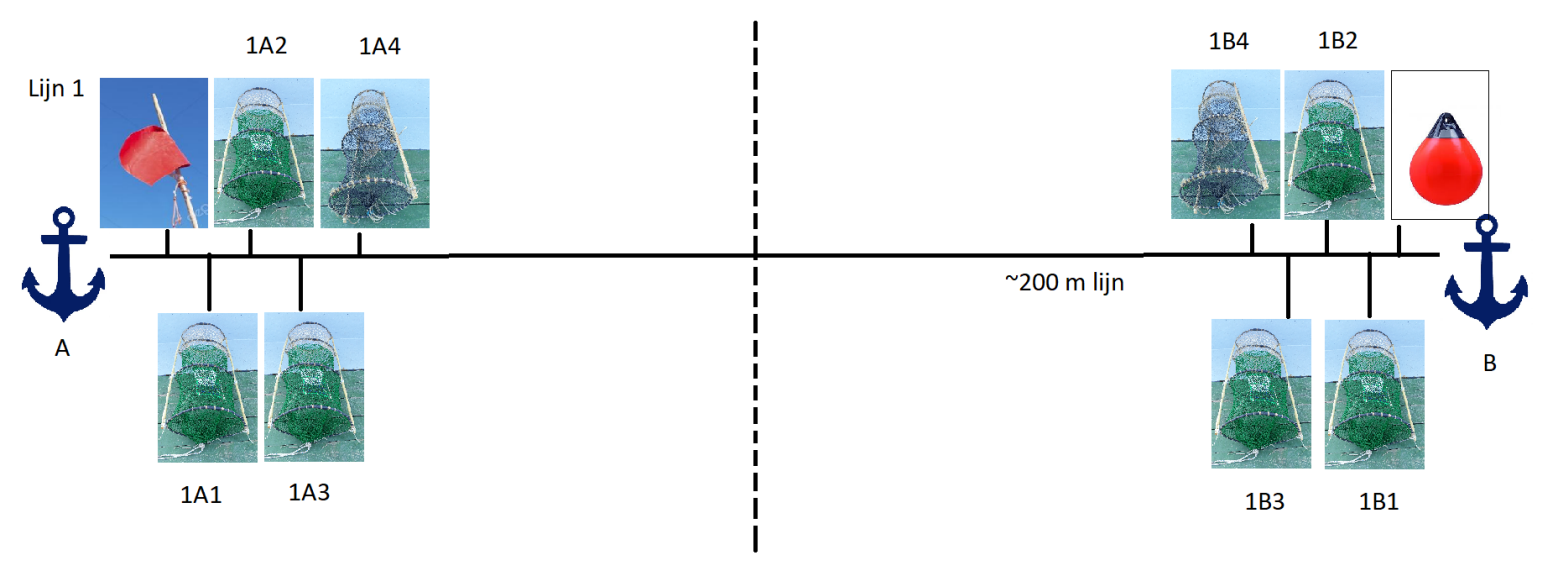

Figuur 5. Schematische weergave van geplaatste kubbenlijn verdeeld over twee percelen (2 locaties). 


\section{Resultaten}

Onderstaand worden de ruwe gegevens gepresenteerd in figuren $(6 \mathrm{t} / \mathrm{m}$ 9) en tabellen $(2 \mathrm{t} / \mathrm{m} 6)$. Interpretatie van de gegevens en nadere analyse zal plaatsvinden nadat percelen in gebruik genomen worden en vervolg bemonsteringen uitgevoerd zijn.

\subsection{Vangsten met mosselkor}

Met de mosselkor zijn 77 trekken uitgevoerd. In 60 van de 77 trekken zijn vissen aangetroffen (Figuur 6 en 7). In de gebieden Inschot en Scheer zijn de hoogste aantallen vis gevangen, voornamelijk bestaande uit grondels (Figuur 7). Daarnaast zijn nog enkele andere soorten gevangen, zoals kleine zeenaald, groene zeedonderpad, sprot, gewone zeedonderpad, schar en schol. In het Scheurrak zijn in 10 monsters kleine zeenaalden aangetroffen. Tabel 2 geeft een overzicht van welke soorten op iedere perceellocatie zijn aangetroffen en in Tabel 3 wordt het aantal soorten per trek weergegeven. Hieruit blijkt dat in Scheer en Inschot niet alleen de aantallen vissen het hoogste was, maar ook het meeste soorten gevangen werden.

In Tabel 4 wordt de gemiddelde lengtes van de vissen weergegeven. Hieruit blijkt dat het voornamelijk de kleinere soorten zijn die gevangen worden (tot ca. $14 \mathrm{~cm}$ ) of juvenielen. Grondels hebben een gemiddelde lengte van 6.2-6.5 cm, met uitzondering van Scheer waar ze gemiddeld een centimeter kleiner waren. In Scheer is er één tong van $30 \mathrm{~cm}$ gevangen.

Uit Figuur 6 blijkt dat het merendeel van de vangst bestond uit andere soorten dan vis. De vangst in het Inschot en Scheer bestond voornamelijk uit stekelhuidigen zoals zeesterren en slangsterren. In alle vijf gebieden werden krabben gevangen, waaronder strandkrab, noordzeekrab, porseleinkrabbetje, hooiwagenkrab, gewimperde zwemkrab, gewone zwemkrab en hemigrapsus $(\mathrm{spec})^{1}$. In Meep en Oosterom werden relatief veel garnalen aangetroffen, voornamelijk gewone garnalen maar ook een aantal aasgarnalen (mysis).

\footnotetext{
${ }^{1}$ Hemigrapsus (spec) is niet gedetermineerd tot op soort. Soorten die eronder vallen zijn o.a. Hemigrapsus takanoi (penseelkrab) en Hemigrapsus sanguineus (blaasjeskrab).
} 


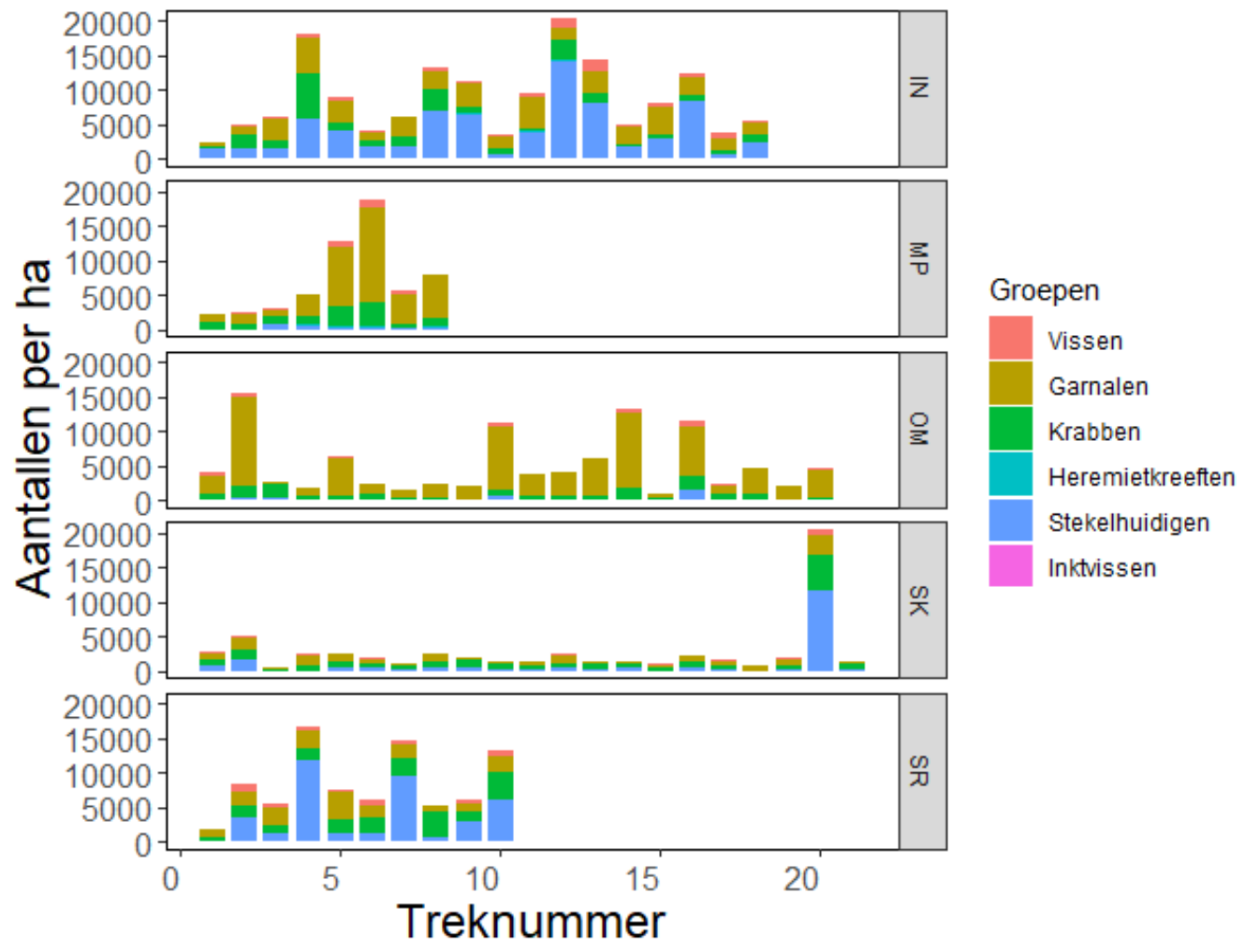

Figuur 2. Aantal gevangen vissen, garnalen, krabben, heremietkreeften, stekelhuidigen en inktvissen per hectare in elk onderzoeksgebied. Eén trek bestaat uit vangsten van zowel de mosselkor als de omhullingskuil. IN=Inschot, $M P=$ Meep, OM=Oosterom, SK=Scheurrak, SR=Scheer. Voor het aantal uitgevoerde trekken per locatie zie Tabel 1.

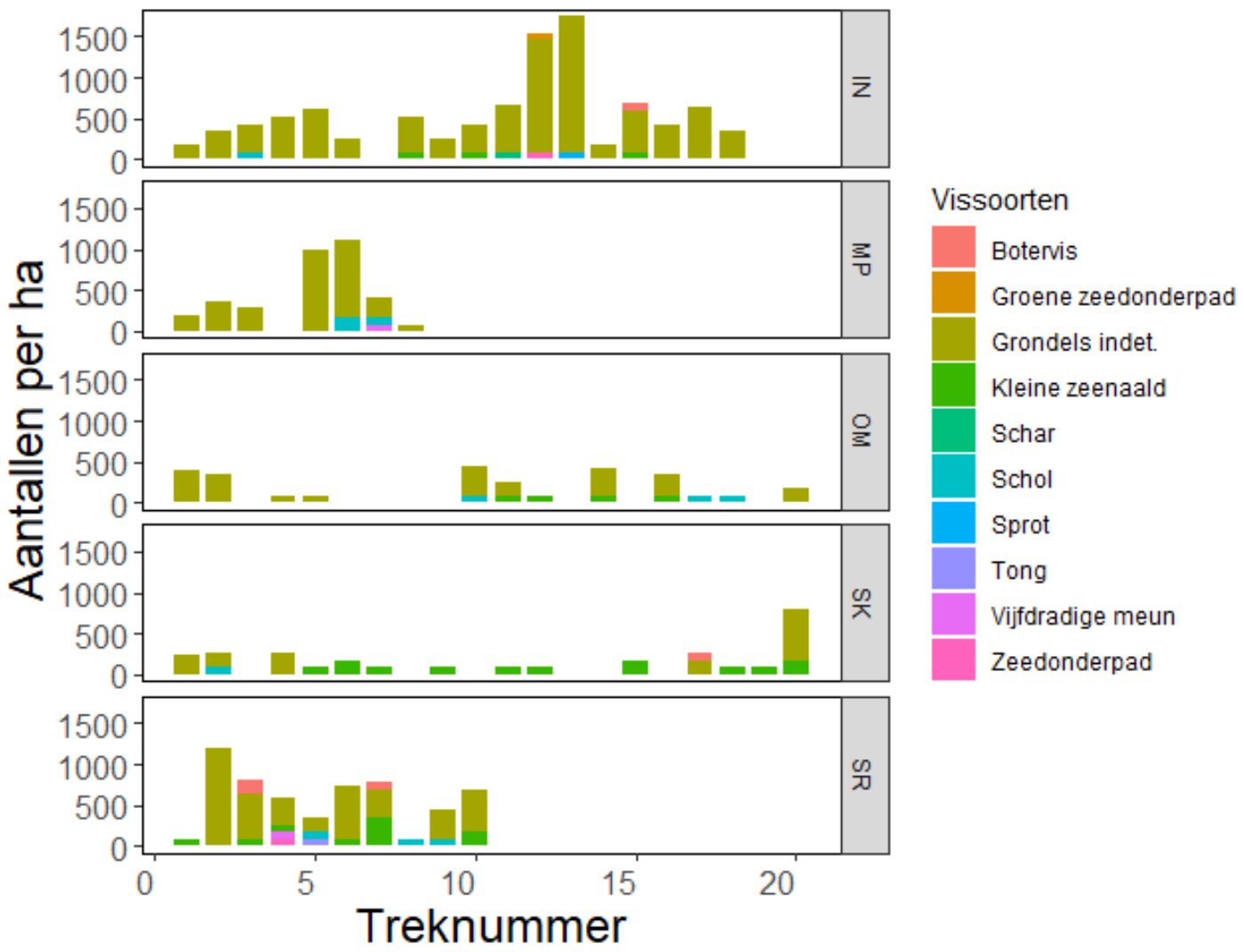

Figuur 1. Aantal vissen per hectare uitgesplitst naar soort per onderzoeksgebied. Eén trek bestaat uit vangsten van zowel de mosselkor als de omhullingskuil. IN=Inschot, $M P=$ Meep, OM=Oosterom, $S K=S c h e u r r a k, S R=S c h e e r$. Voor het aantal uitgevoerde trekken per locatie, zie Tabel 1. In een aantal trekken zijn geen vissen gevangen, vandaar de ontbrekende balken bij sommige treknummers. 
Tabel 2. Overzicht van (vis)soorten gevangen met de mosselkor per onderzoeksgebied.

\begin{tabular}{|c|c|c|c|c|c|c|}
\hline Soorten & Latijnse naam & Inschot & Meep & Oosterom & Scheurrak & Scheer \\
\hline Botervis & Pholis gunnellus & $x$ & & & $x$ & $x$ \\
\hline Groene zeedonderpad & Taurulus bubalis & $x$ & & & & \\
\hline Grondels sp. & Pomatoschistus sp. & $x$ & $x$ & $x$ & $x$ & $x$ \\
\hline Kleine zeenaald & $\begin{array}{l}\text { Syngnathus } \\
\text { rostellatus }\end{array}$ & $x$ & & $x$ & $x$ & $x$ \\
\hline Schar & Limanda limanda & $x$ & & & & \\
\hline Schol & Pleuronectes platessa & $x$ & $x$ & $x$ & $x$ & $x$ \\
\hline Sprot & Sprattus sprattus & $x$ & & & & \\
\hline Tong & Solea solea & & & & & $x$ \\
\hline Vijfdradige meun & Ciliata mustela & & $x$ & & & $x$ \\
\hline Zeedonderpad & $\begin{array}{l}\text { Myoxocephalus } \\
\text { scorpius }\end{array}$ & $x$ & & & & $x$ \\
\hline Totaal aantal vissoorten & & 8 & 3 & 3 & 4 & 7 \\
\hline Zeester & Asterias rubens & $\mathrm{x}$ & $\mathrm{x}$ & $\mathrm{x}$ & $x$ & $x$ \\
\hline Strandkrab & Carcinus maenas & $x$ & $x$ & $x$ & $x$ & $x$ \\
\hline Slangster & Ophiura ophiura & $x$ & $x$ & $x$ & & $x$ \\
\hline Gewone heremietkreeft & Pagurus bernhardus & $x$ & $x$ & $x$ & & $x$ \\
\hline Gewone garnaal & Crangon crangon & $x$ & $x$ & $x$ & $x$ & $x$ \\
\hline Steurgarnaal & Palaemon sp. & & & & & $x$ \\
\hline Porceleinkrabbetje & Pisidia longicornis & $x$ & $x$ & $x$ & & $x$ \\
\hline Hooiwagenkrab & Macropodia rostrata & $x$ & & $x$ & $x$ & $x$ \\
\hline Noordzeekrab & Cancer pagurus & & & & $x$ & \\
\hline Zeeappel & $\begin{array}{l}\text { Psammechinus } \\
\text { miliaris }\end{array}$ & $x$ & & $x$ & & \\
\hline Gewimperde zwemkrab & Liocarcinus navigator & $x$ & & $x$ & & \\
\hline Gewone zwemkrab & Liocarcinus holsatus & $x$ & $x$ & $x$ & $x$ & \\
\hline Hemigrapsus & Hemigrapsus sp. & & & & $x$ & $x$ \\
\hline Dwerginktvis & Sepiola atlantica & $x$ & & & & \\
\hline $\begin{array}{l}\text { Totaal aantal overige } \\
\text { soorten }\end{array}$ & & 11 & 7 & 10 & 7 & 9 \\
\hline $\begin{array}{l}\text { Totaal aantal gevangen } \\
\text { soorten }\end{array}$ & & 19 & 10 & 13 & 11 & 16 \\
\hline
\end{tabular}

Tabel 3. Gemiddeld aantal vissoorten (en SD) gevangen per trek met de mosselkor.

\begin{tabular}{|l|c|}
\hline Gebied & Aantal vissoorten/trek \\
\hline Inschot & $1.5 \pm 0.7$ \\
\hline Meep & $1.4 \pm 0.8$ \\
\hline Oosterom & $1.3 \pm 0.5$ \\
\hline Scheurrak & $1.2 \pm 0.4$ \\
\hline Scheer & $2.2 \pm 1.0$ \\
\hline
\end{tabular}


Tabel 4. Gemiddelde lengte (en SD) van de vissoorten gevangen met de mosselkor in ieder onderzoeksgebied.

\begin{tabular}{|l|c|c|c|c|c|}
\hline \multicolumn{3}{|l}{} & \multicolumn{3}{l}{ Lengte $(\mathrm{cm})$} \\
\hline Vissoort & Inschot & Meep & Oosterom & Scheurrak & Scheer \\
\hline Botervis & $12.0 \pm 0.0$ & & & $10.0 \pm 0.0$ & $13.7 \pm 0.6$ \\
\hline Groene zeedonderpad & $7.0 \pm 0.0$ & & & & \\
\hline Grondels sp. & $6.3 \pm 0.9$ & $6.4 \pm 1.5$ & $6.5 \pm 0.9$ & $6.2 \pm 1.1$ & $5.3 \pm 0.9$ \\
\hline Kleine zeenaald & $7.2 \pm 3.3$ & & $9.8 \pm 1.3$ & $8.8 \pm 1.8$ & $8.4 \pm 1.6$ \\
\hline Schar & $5.0 \pm 0.0$ & & & & \\
\hline Schol & $9.0 \pm 0.0$ & $8.5 \pm 0.7$ & $7.0 \pm 1.0$ & $10.0 \pm 0.0$ & $8.0 \pm 1.0$ \\
\hline Sprot & $6.0 \pm 0.0$ & & & & \\
\hline Tong & & & & & $30.0 \pm 0.0$ \\
\hline Vijfdradige meun & & $12.0 \pm 0.0$ & & & $9.0 \pm 0.0$ \\
\hline Zeedonderpad & $6.0 \pm 0.0$ & & & & $12.0 \pm 0.0$ \\
\hline
\end{tabular}

\subsection{Vangsten met kubben}

In 68 van de 152 kubben zijn vissen gevangen (Figuur 8). Vijfdradige meun is de meest gevangen soort en werd in elk gebied gevangen (aangetroffen in 66 verschillende kubben), gevolgd door steenbolk (aangetroffen in 10 kubben), aal, puitaal en zeedonderpad (Figuur 9). Van de laatste drie soorten slechts één exemplaar gevangen. Op drie locaties (Meep, Oosterom, Scheurrak) werden naast vijfdradige meun ook andere vissoorten gevangen.

In de kubben zijn in totaal 14 verschillende soorten aangetroffen, waarvan vijf vissoorten (Tabel 5 en Figuur 8). Strandkrab werd in elke kub aangetroffen en was de meest gevangen soort. Ook werd gewone garnaal regelmatig aangetroffen (in 26 kubben) samen met zeesterren (in 34 kubben). 


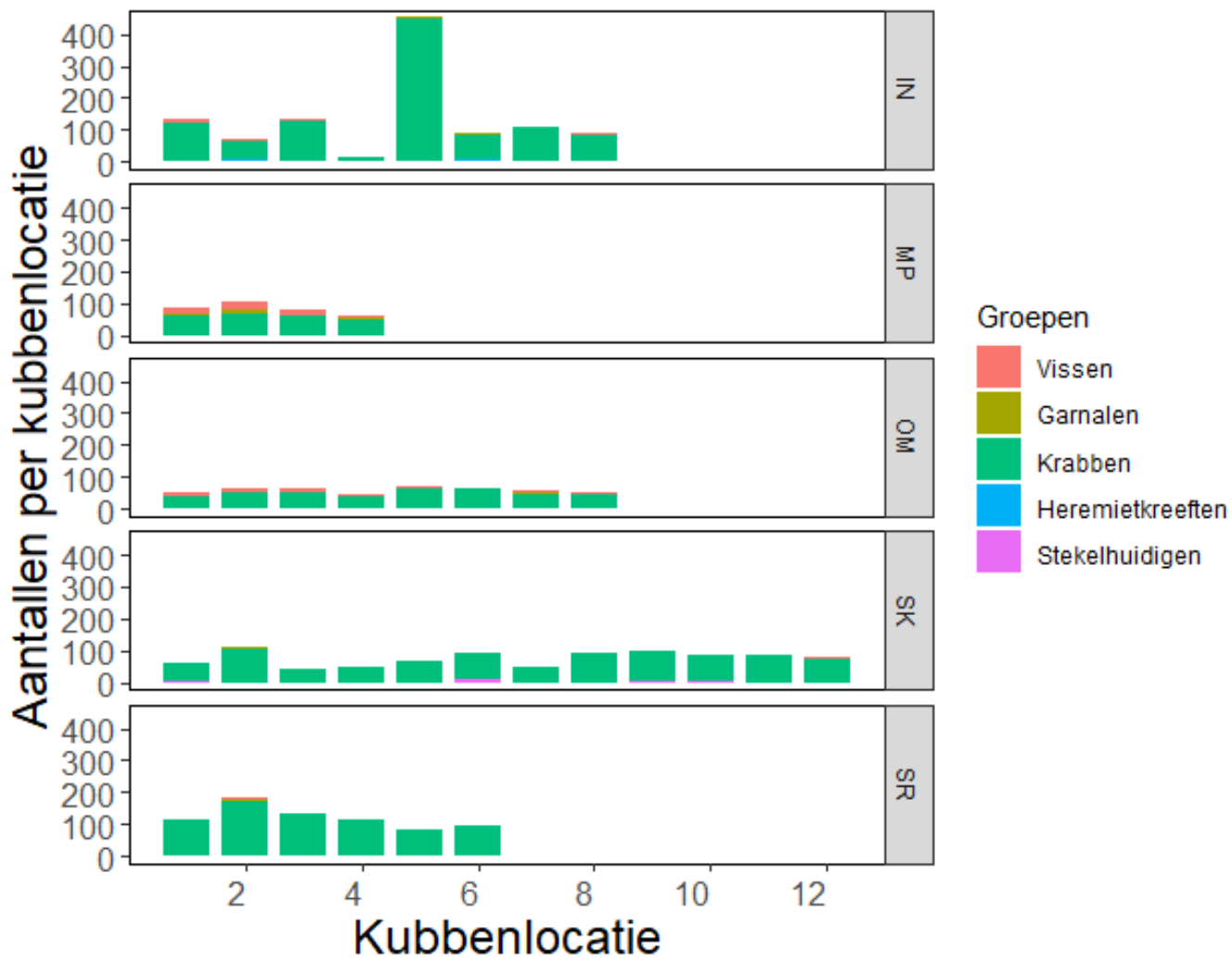

Figuur 3. Aantal gevangen vissen, garnalen, krabben, heremietkreeften en stekelhuidigen per kubbenlocatie in elk onderzoeksgebied. Elke kubbenlocatie bestaat uit vier kubben waarvan de vangst bij elkaar is opgeteld. IN=Inschot, $M P=M e e p, O M=$ Oosterom, $S K=S c h e u r r a k, S R=S c h e e r$. Het aantal kubbenlocaties per gebied staat weergegeven in Tabel 1.

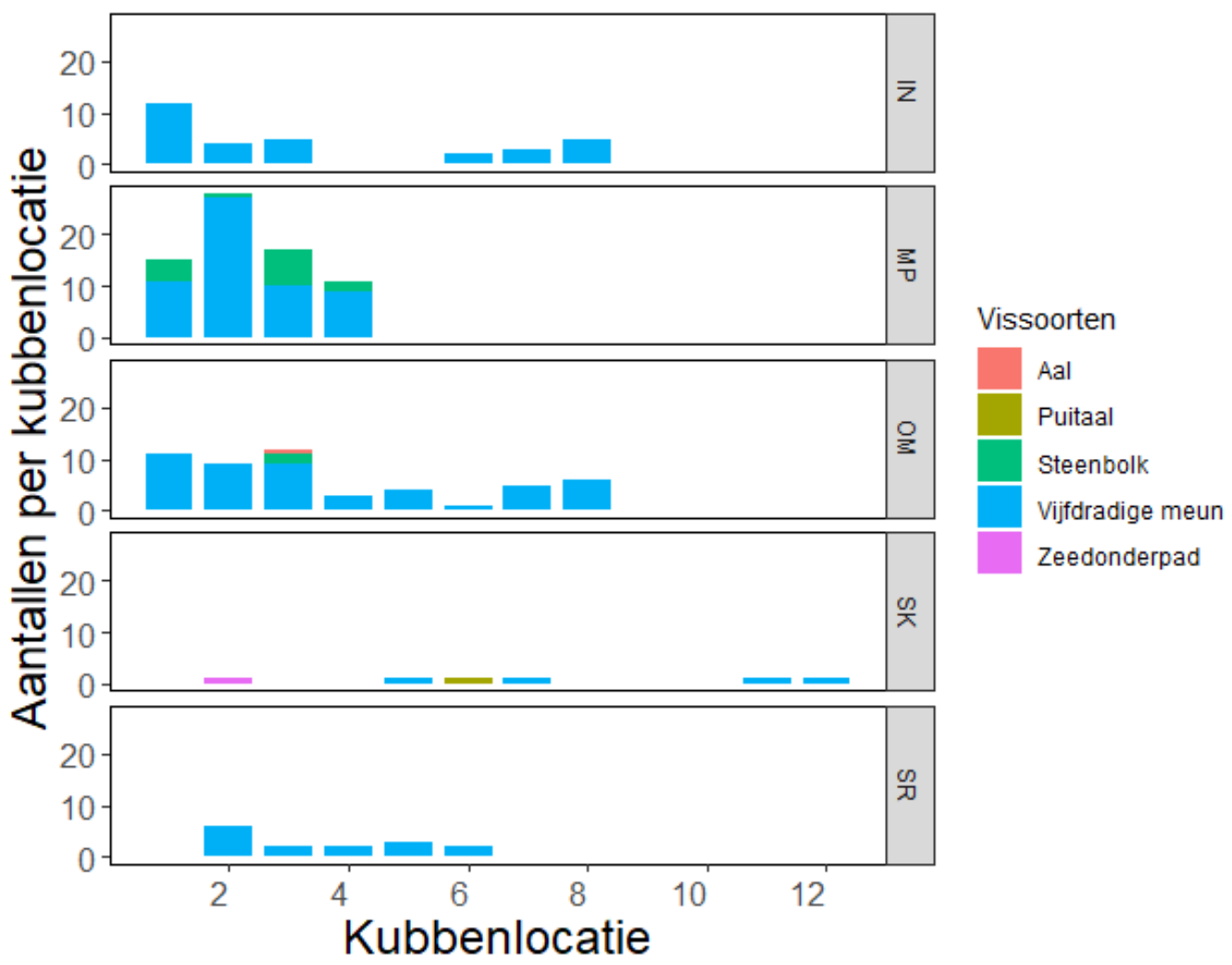

Figuur 4. Aantal gevangen vissen per kubbenlocatie in elke onderzoeksgebied. Elke kubbenlocatie bestaat uit vier kubben waarvan de vangst bij elkaar is opgeteld. IN=Inschot, MP = Meep, OM=Oosterom,

$S K=$ Scheurrak, $S R=S c h e e r$. Het aantal kubbenlocaties per gebied staat weergegeven in Tabel 1. 
Tabel 5. Overzicht van de gevangen (vis)soorten in kubben per onderzoeksgebied. IN=Inschot, MP=Meep, OM=Oosterom, $S K=$ Scheurrak, $S R=$ Scheer.

\begin{tabular}{|c|c|c|c|c|c|c|}
\hline Soorten & Latijnse naam & IN & MP & OM & SK & SR \\
\hline Vijfdradige meun & Ciliata mustela & $\mathrm{X}$ & $X$ & $\mathrm{X}$ & $\mathrm{X}$ & $\mathrm{X}$ \\
\hline Steenbolk & Trisopterus luscus & & $\mathrm{X}$ & $\mathrm{X}$ & & \\
\hline Aal & Anguilla anguilla & & & $\mathrm{X}$ & & \\
\hline Zeedonderpad & Myoxocephalus scorpius & & & & $\mathrm{X}$ & \\
\hline Puitaal & Zoarces viviparus & & & & $\mathrm{X}$ & \\
\hline Totaal aantal vissoorten & & 1 & 2 & 3 & 3 & 1 \\
\hline Strandkrab & Carcinus maenas & $\mathrm{X}$ & $x$ & $\mathrm{X}$ & $\mathrm{x}$ & $\mathrm{X}$ \\
\hline Gewone zwemkrab & Liocarcinus holsatus & $\mathrm{X}$ & $X$ & & & \\
\hline Hooiwagenkrab & Macropodia rostrata & $\mathrm{X}$ & & & $\mathrm{X}$ & \\
\hline Gewone heremietkreeft & Pagurus bernhardus & $\mathrm{X}$ & & $\mathrm{X}$ & & \\
\hline Zeester & Asterias rubens & $\mathrm{X}$ & & $\mathrm{X}$ & $\mathrm{X}$ & $\mathrm{X}$ \\
\hline Slangster & Ophiura ophiura & $\mathrm{X}$ & & & & \\
\hline Gewone garnaal & Crangon crangon & $x$ & $x$ & $\mathrm{X}$ & $\mathrm{X}$ & $X$ \\
\hline Rugstreep steurgarnaal & Palaemon macrodactylus & $\mathrm{X}$ & & & & \\
\hline Gezaagde steurgarnaal & Palaemon serratus & & & $\mathrm{X}$ & & \\
\hline Totaal aantal overige soorten & & 8 & 3 & 5 & 4 & 3 \\
\hline Aantal gevangen soorten & & 9 & 5 & 8 & 7 & 4 \\
\hline
\end{tabular}

Tabel 6. Gemiddelde lengte (en SD) van de vissoorten gevangen in de kubben in ieder onderzoeksgebied. De soorten waarvoor geen standaard deviatie is weergegeven is er slechts één individu gevangen.

\begin{tabular}{|l|c|c|c|c|c|}
\hline \multirow{2}{*}{} & \multicolumn{5}{|c|}{ Lengte $(\mathrm{cm})$} \\
\hline Vissoort & Inschot & Meep & Oosterom & Scheurrak & Scheer \\
\hline Vijfdradige meun & $11.1 \pm 1.7$ & $11.5 \pm 1.7$ & $11.7 \pm 1.6$ & $11.8 \pm 1.7$ & $11.9 \pm 1.2$ \\
\hline Steenbolk & & $14.4 \pm 1.0$ & $14.0 \pm 1.4$ & & \\
\hline Aal & & & 39.0 & & \\
\hline Puitaal & & & & 16.0 & \\
\hline Zeedonderpad & & & & 16.0 & \\
\hline
\end{tabular}




\section{Dankwoord}

We bedanken de bemanning van de BRU68 voor hulp en assistentie bij de bemonstering. Ook bedanken we Dries Wiersma en Marius van Malsen voor hulp en het beschikbaar stellen van materiaal voor het kunnen uitvoeren van de bemonstering. 


\section{Literatuur}

Bolle, L.J.; Dijkman Dulkes, H.J.A.; Pasterkamp, T.L.; Vries, M. de, 2019. Reisverslagen Sole net Survey (SNS) en Demersal Fish Survey (DFS) 2018. CVO rapport / Centrum voor Visserijonderzoek 19.007

Glorius, S.T., Rippen, A.D., Van Stralen, M.R. en Jansen, J.M. (2012) PRODUS 3 - Deelrapport bodemschaap en zuigkordata: Effecten van mosselzaadvisserij op het bodemleven van de Waddenzee. Wageningen Marine Research, rapport C162/12.

Ministerie van Landbouw Natuur en Voedselkwaliteit, Vogelbescherming Nederland, De Waddenvereniging, Stichting Wad, De Vereniging Natuurmonumenten, Producentenorganisatie Mosselcultuur, 2008. Convenant transitie mosselsector en natuurherstel Waddenzee. 


\section{Verantwoording}

Rapport C117/20

Projectnummer: 4318100340

Dit rapport is met grote zorgvuldigheid tot stand gekomen. De wetenschappelijke kwaliteit is intern getoetst door een collega-onderzoeker en het verantwoordelijk lid van het managementteam van Wageningen Marine Research

Akkoord

O. van Keeken

Onderzoeker

Handtekening:

Datum:

21 december 2020

Akkoord:

Drs. J. Asjes

Manager Integratie

Handtekening:

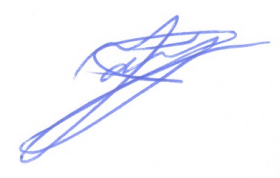

Datum:

21 december 2020 
Wageningen Marine Research 
T: $+31(0) 317480900$

E: marine-research@wur.nl

www.wur.nl/marine-research

Bezoekers adres:

- Ankerpark 271781 AG Den Helder

- Korringaweg 7, 4401 NT Yerseke

- Haringkade 1, 1976 CP IJmuiden
Wageningen Marine Research levert met kennis, onafhankelijk wetenschappelijk onderzoek en advies een wezenlijke bijdrage aan een duurzamer, zorgvuldiger beheer, gebruik en bescherming van de natuurlijke rijkdommen in zee-, kust- en zoetwatergebieden.
Wageningen Marine Research is onderdeel van Wageningen University \& Research. Wageningen University \& Research is het samenwerkingsverband tussen Wageningen University en Stichting Wageningen Research en heeft als missie: 'To explore the potential of nature to improve the quality of life' 